\title{
REPRESENTAÇÃO SOCIOCULTURAL DO CONHECIMENTO (RSC): UM OLHAR A PARTIR DO PENSAMENTO DE ANTONIO GARCIA GUTIERREZ E BOAVENTURA DE SOUZA SANTOS
}

\section{SOCIOCULTURAL KNOWLEDGE REPRESENTATION (SKR): AN ANALYSIS FROM THE THOUGHT OF ANTONIO GARCIA GUTIERREZ AND BOAVENTURA DE SOUZA SANTOS}

\author{
Sale Mário Gaudêncioa \\ Maria Elizabeth Baltar Carneiro de Albuquerque ${ }^{b}$ \\ Gisele Rocha Côrtes ${ }^{\circ}$
}

\begin{abstract}
RESUMO
Esse trabalho traz como Objetivo apresentar um olhar alternativo de aproximação interdisciplinar para Representação do Conhecimento a partir da aproximação entre a Desclassificação do Conhecimento de Antonio Garcia-Gutierrez e a Descolonização do Saber de Boaventura de Sousa Santos, a fim de contribuir para uma Representação Sociocultural do Conhecimento (RSC). Para responder ao que fora levantado, usa-se como Metodologia uma pesquisa de natureza teórica, bibliográfica e exploratória e tendo como tipologia uma posição qualitativa. A esta investigação, vê-se como Resultado primaz, o fato de revelar que para atuar com a RSC, antecipadamente, é importante se "despir" do pensamento dominante, fazendo mister um repensar em torno de teorias, métodos e práticas informacionais tradicionais, pois só é possível pensar sob a ótica e lógica da Desclassificação e da Descolonização do Conhecimento se for favorecida, mentalmente, uma Reconexão Cognitiva e ressignificação da vivência em busca de um movimento que oportunize um perceber dialético, crítico, construtivista e interseccional. Assim, mostra-se como Conclusão central, o fato de ainda se observar a carência de mais investimentos investigativos em pesquisas direcionadas ao processo de Desclassificação e Descolonização do Conhecimento, com vistas a mostrar ao Profissional da Informação que existem possibilidades alternativas de atuação, seja no âmbito acadêmico, político ou em direção à sociedade.
\end{abstract}

Descritores: Representação Sociocultural do Conhecimento (RSC). Representação do Conhecimento. Desclassificação do Conhecimento. Descolonização do Saber. Sociologia do Conhecimento.

\footnotetext{
a Doutor em Ciência da Informação pela Universidade Federal da Paraíba (UFPB). Bibliotecário da Universidade Federal Rural do Semi-Árido (UFERSA). E-mail: mario@ufersa.edu.br.

b Doutora em Letras pela Universidade Federal da Paraíba (UFPB). Docente do Programa de PósGraduação em Ciência da Informação da Universidade Federal da Paraíba (UFPB). E-mail: ebaltar2007@gmail.com.

c Doutora em Sociologia pela Universidade Estadual Paulista Júlio de Mesquita Filho (Unesp). Docente do Programa de Pós-Graduação em Ciência da Informação da Universidade Federal da Paraíba (UFPB). E-mail: giselerochacortes@gmail.com.
} 


\section{INTRODUÇÃO}

Vê-se no Campo da Ciência da Informação, especificamente da Organização e Representação da Informação e do Conhecimento, que no último século, os debates eram efetivados prioritariamente à luz dos Paradigmas Físico e Cognitivo (CAPURRO, 2003), seja por uma questão política ou conjuntural.

Isso ocorre ainda porque de acordo com Tabosa, Tavares e Nunes (2016, p. 296), por um lado, ainda estamos imersos sob um modelo hegemônico, todavia, por outro lado, nos direcionam ao encontro do Paradigma Sociocultural, especialmente porque os Paradigmas Dominantes "[...] já não se" mostram eficazes "para dar conta dos desafios de cunho social, impetrados pela sociedade atual e apresentam, como possível solução, a consolidação do paradigma social, de forma efetiva".

Esta ideia vai ao encontro do que pensa Nascimento (2006, p. 33), que, por meio de sua reflexão através do estudo sobre a Abordagem Sociocultural da Informação, entendeu que é preciso abrir espaço "[...] para um fenômeno social de informação coletiva, estruturas de conhecimento e instituições de memória das comunidades discursivas".

Observando estes aspectos e trazendo um posicionamento ao âmbito da Representação do Conhecimento, vê-se que este movimento ocorre em função de enfrentar-se

[...] hoje, na pesquisa em Organização e Representação do Conhecimento, dificuldades de tratar documentos em face à manifestação das diversidades sociais, culturais e políticas. Que ferramentas teremos de desenvolver para dar conta da produção do conhecimento e de sua recepção quando verificamos que as referências da documentação ainda estão assentadas nas hierarquias, no privilégio dos substantivos (as essências) e, muitas vezes, em parâmetros universais? (LARA, 2013, p. 238).

Nesta mesma linha de pensamento, apresenta-se a provocação de Saldanha e Souza (2017, p. 16), onde:

A grande questão que se coloca aqui: em que medida as teorias propriamente ditas e os métodos da OC problematizam o real em seu estatuto de formação culturalmente tecida, ou seja, qual a capacidade de refletir sobre a condição social e qual a propensão de lutar pelas mudanças (de seus construtos e daqueles imersos na complexidade do mundo social)?

Com isso, percebe-se que existe uma propensão a se adentrar em uma Crise Paradigmática, provocando a busca por modelos capazes de transpor os limites do 
que os autores compreendem como um soterramento do campo, ou seja, uma área restrita por uma "teoria barroca", que reflete o espaço científico e o Profissional da Informação, o qual, por sua vez, se vê apenas através de "espelhos turvos", como asseveram Saldanha e Souza (2017).

O domínio ainda engatinha rumo a um repensar de suas teorias e práticas, que, até o momento, ainda são norteadas e cristalizadas privilegiadamente pelos paradigmas Físico e Cognitivo da Ciência da Informação (CAPURRO, 2003).

Nesse sentido, a investigação se justifica por buscar compreender que ela reflete inquietações teórico-metodológicas no domínio da Organização e Representação da Informação e do Conhecimento, visto que encontramo-nos imersos em uma hiper-realidade cultural, que nos provoca a rever a forma como o processo representacional tem sido feito ao longo da história, especialmente se pensarmos que novas demandas estão sendo lançadas a todo o momento e que as respostas apresentadas ainda são majoritariamente calcadas em métodos e técnicas tradicionais, que não respondem mais de maneira adequada à contemporaneidade.

Os estudos em torno dos impactos causados pelo fenômeno informação/conhecimento na contemporaneidade, especialmente no âmbito da Organização e Representação da Informação e do Conhecimento, exortam por uma suspensão epistemológica, de uma ressignificação teórica e de um realinhamento metodológico que sejam capazes de olhar o objeto de estudo sob múltiplos prismas, algo que os atuais recortes investigativos não permitem, em sua plenitude.

Por esse motivo, veem-se no domínio da Organização e Representação da Informação e do Conhecimento, Buracos Informacionais, ou seja, Desigualdades Socioinformacionais, demonstrando que ainda há muito por construir, ressignificar, refletir e debater.

Portanto, é nesse sentido que se objetiva aqui, apresentar um olhar alternativo de aproximação interdisciplinar para a Representação do Conhecimento, a partir da aproximação entre a Desclassificação do Conhecimento de Antonio García Gutiérrez e a Descolonização do Saber de Boaventura de Sousa Santos, ambas tratadas aqui como proposições reflexivas e contributivas para o enriquecimento do processo de Representação do Conhecimento.

Para dar conta deste debate, esta análise foi construída metodologicamente por meio de uma pesquisa de natureza: teórica, bibliográfica e exploratória e tendo 
como tipologia uma posição qualitativa.

Dito isso, tem-se aqui um investimento investigativo para aproximar a Representação com a Sociologia do Conhecimento e, assim, oferecer ao pesquisador a oportunidade de amplificar o seu prisma investigativo.

\section{REPRESENTAÇÃO SOCIOCULTURAL DO CONHECIMENTO (RSC)}

A história da Representação do Conhecimento sempre esteve associada à ideia de o sujeito observar um fenômeno no mundo natural para que, posteriormente, Ihe fosse possível atribuir um significado enquanto objeto e, assim, este, passado pelas transformações culturais devidas, por posições universais, convenções institucionais, aceites sociais e marcos históricos, pudesse adquirir sentido e importância na humanidade.

Por esse motivo, emergem e se consolidam os Sistemas de Organização do Conhecimento (SOCs) tradicionais, com o intuito de traduzir a linguagem natural (senso comum) para a linguagem artificial, ou seja, sistemas científicos que permitem a Representação, Organização e Recuperação da Informação em estruturas do conhecimento registrado. Seguindo esta linha de pensamento, compreende-se por SOCs, aqueles que:

[...] abrangem todos os tipos de esquemas que organizam e representam o conhecimento, por exemplo, as classificações, taxonomias, tesauros e ontologias. SOCs são sistemas conceituais semanticamente estruturados que contemplam termos, definições, relacionamentos e propriedades dos conceitos. Na organização e recuperação da informação, os SOC cumprem o objetivo de padronização terminológica para facilitar e orientar a indexação e os usuários. Quanto à estrutura variam de um esquema simples até o multidimensional, enquanto que ( $\mathrm{sic}$ ) suas funções incluem a eliminação da ambiguidade, controle de sinônimos ou equivalentes e estabelecimento de relacionamentos semânticos entre conceitos (CARLAN; MEDEIROS, 2011, p. 54).

Dialogando com as autoras mencionadas e trazendo ao contexto problematizado, Lara e Mendes (2017, p. 375) observam que "os padrões dos Sistemas de Organização do Conhecimento (SOCs) não surgem num vazio, mas estão intimamente relacionados às formas de organizar o mundo que são, sobretudo, culturais".

Em virtude disso, ao longo do tempo, até por uma questão conjuntural, a Ciência da Informação pensou o fenômeno informacional a partir das Dimensões 
Físicas, Cognitivas e Sociais (CAPURRO, 2003), todavia foram privilegiados alguns Paradigmas como o Físico e o Cognitivo em detrimento do Social.

Outrora, considerando as novas demandas informacionais, se requerem Mudanças Paradigmáticas no sentido de potencializar abordagens alternativas para tratar, por exemplo, documentos voláteis, híbridos ou aqueles que foram silenciados, marginalizados ou esquecidos pelos principais SOCs tradicionais, como a Classificação Decimal Dewey (CDD), a Classificação Decimal Universal (CDU) e o Anglo American Cataloguing Rules (AACR2), cuja atuação privilegiou, ao longo da história, temáticas voltadas a um pensar hegemônico dos países do Norte em detrimento dos países do Sul.

A exemplo disso, está o caso de como a Literatura de Cordel é representada nos SOCs tradicionais. Ela não é incluída como uma subcategoria da classe da Literatura, mas está classificada como Folclore. A Literatura, aqui, privilegia essencialmente a dita cultura elitista, com profunda ênfase aos países desenvolvidos. Para Albuquerque (2011, p. 43), "as classificações bibliográficas, até o presente momento, inserem a literatura de cordel no âmbito do folclore. Tal tratamento é inconsistente quando se trata de um instrumento de controle de vocabulário, que representa a expressão da cultura popular".

Numa outra frente, mas com o mesmo nível de importância, está a pesquisa de Sousa e Tolentino (2017, p. 200), que estuda os "aspectos machistas na organização do conhecimento" a partir da "representação da mulher em instrumentos documentários". Nela, observou-se:

[...] como os instrumentos reforçam o sentido de superioridade do homem sobre a mulher, a dominação patriarcal e a afirmação do papel feminino único enquanto esposa, dona de casa e mãe. As relações apontadas não designam formas de libertação entre homens e mulheres, não reproduzem o idêntico, não está dada. As mulheres são dominadas coletiva e individualmente pelo masculino, conforme foi possível constatar no recorte do Tesauro para Estudos de Gênero e Sobre Mulheres (TEG), no Tesauro Jurídico do Superior Tribunal de Justiça (TJ STJ) e no Anglo American Cataloguing Rules, $2^{\mathrm{a}}$ edição (AACR2r).

Percebendo tal cenário, esta investigação aborda a aplicação da Representação do Conhecimento a partir da Dimensão Sociocultural da Ciência da Informação, para que se permita construir um diálogo capaz de incluir àqueles (as) que estão à margem, que são excluídos (as), àqueles que compõem a "ralé", conforme 
identifica Souza (2017), ou ainda como demonstra García-Gutiérrez (2006) com sua exposição sobre os "favelados' do conhecimento".

Ao permitir isso, será possível favorecer o que Hall $(2015,2016)$ chama de reconhecimento de uma identidade cultural na contemporaneidade, com o objetivo de compreender as diversas maneiras de Manifestações Socioculturais que implicam diretamente na forma como são vistas e concebidas as memórias coletivas (HALBWACHS, 1990).

É notadamente em virtude disso que têm aumentado os estudos que permitem amplificar positivamente as forças de tensão para provocar novas possibilidades ao campo científico. Renomados pesquisadores já vêm apontando para uma emergência de revisão e realinhamento epistemológico, frente às novas Demandas Sociais e Condições Culturais.

Varela e Barbosa (2012, p. 148), ao investigarem a Dimensão Social e Cognitiva na Organização e Representação do Conhecimento, perceberam que "compreender fenômenos significa ser competente para formular hipóteses ou ideias (sic) sobre as relações causais [...]".

López-Huertas (2013, p. 234-235, tradução nossa), ao traçar o panorama da pesquisa em Organização do Conhecimento em sua Dimensão Social, Cultural e Política, considerando a formação profissional, ética, cultura e identidade, contextos e sustentabilidade, se mostra favorável à configuração de um novo desenho para construção dos SOCs. Para isso, quatro princípios precisam ser considerados, a saber:

1. As funções da $\mathrm{OC}^{2}$ excedem em muito o escopo tradicional de recuperação de informação no sentido estrito e devemos nos preparar para responder a este e outros contextos [...]. 2. A OC também é uma ótima fonte de informação e um método eficaz para avaliar contextos específicos que exigem a identificação de novos indicadores de qualidade $[\ldots .$.$] . 3. [...] a transversalidade deve ser um imperativo no$ desenho de sistemas de informação fazendo com que este tema tenha uma grande importância [...]. 4. [...] é preciso repensar os fundamentos que regem a construção de sistemas de organização do conhecimento. É necessário encontrar alternativas que passem por uma revisão criativa dos fundamentos que governam esses sistemas.

\footnotetext{
1 O termo deriva do conceito de "favela", cuja explicação dada por Valéria Grace Costa e José Antônio Sena do Nascimento (2005, p. 3800-3801) é: "O IBGE, para o Censo, utiliza a nomenclatura de aglomerado subnormal para designar os setores censitários do tipo especial que formam as áreas de favelas e similares (mocambos, vilas, palafitas, invasões) [...] assentamentos ou aglomerados subnormais, bolsões de pobreza/ áreas de interesse social, áreas de subhabitação (favelas)".

2 A sigla refere-se ao termo "Organização do Conhecimento".
} 
Seguindo essa perspectiva, rumo a um repensar teórico e metodológico, Lara (2013, p. 240), ao refletir sobre os problemas da Organização do Conhecimento na contemporaneidade, observa que:

[...] Conceitos-chave para a contemporaneidade - interculturalidade, heterogeneidade, diversidade, diferença, instabilidade - apontam para deslocamentos em relação à situação vivida desde o iluminismo e exigem novas práticas que considerem a negociação, os intercâmbios, os trabalhos colaborativos.

Não obstante a isso, "[...] as estruturas e categorias tradicionais não mais dão conta da complexidade contemporânea, o que leva a uma parafernália de conceitos que tentam dar nome e enquadramento àquilo que escapa à categorização" (LARA, 2013, p. 240). A isso é feito um adendo, observando que os SOCs precisam refletir "as expressões do que entendem como as categorias sociais e culturais de seu tempo, das quais derivam práticas e procedimentos para com a informação" (LARA; MENDES, 2017, p. 377).

Baseando-se nestes posicionamentos, tanto López-Huertas (2013, p. 26), quanto Lara (2013, p. 244), percebem que os "conceitos binários" para primeira e a "classificação binária" para segunda, diminuem "a complexidade do real, reduzindo também a possibilidade do sentido" e do fator inclusivo do Ator Social, fazendo com que, qualquer iniciativa de inclusão da multiculturalidade e da transversalidade não seja potencializada em sua plenitude. Trivelato e Moura (2017, p. 397) notam que

[...] no campo da organização da informação e do conhecimento, ainda se faz necessário à incorporação de reflexões e práticas profissionais que oportunizem ao reconhecimento, a reciprocidade a conexão entre os sujeitos sociais a partir da consolidação de instrumentos que possam revelar a diversidade de atores sociais que constituem a sociedade e a produção do conhecimento.

Para contribuir com este debate, é salutar se distanciar do discurso retórico cristalizado e observar como Varela e Barbosa (2013, p. 281), que tratam a Organização do Conhecimento associada à figura do Sujeito Social, no sentido de proporcionar ao mesmo acesso pleno ao conhecimento, independentemente do seu grupo de pertença. É tendo em vista esses princípios que se consegue promover, de forma interconectada, "o caráter técnico, social e mediador da organização do conhecimento" (VARELA; BARBOSA, 2013, p. 281).

Isso se faz no sentido de buscar construir "[...] um contraponto aos limites impostos pelas estruturas de organização do conhecimento sob a forma de árvores, além de permitir organizar categorias e conceitos em sistemas transversais" (LARA; 
MENDES, 2017, p. 380).

Contudo, é possível perceber que na primeira fase do século XXI também se têm produzido avanços direcionados ao âmbito Sociocultural da Organização do Conhecimento. Segundo Gomes, Evangelista, Martinez-Ávila e Grácio (2017, p. 384), em:

[...] relação ao aspecto cultural da Organização do Conhecimento, avanços significativos vêm sendo alcançados em âmbito internacional, na medida em que se observam estudos dedicados a repensar as práticas, os valores, os contextos e os atores envolvidos na Organização do Conhecimento.

Mesmo havendo estudos direcionados ao campo, observa-se que a Organização do Conhecimento aplicada à Dimensão Sociocultural da Ciência da Informação, ainda se encontra em fase de Estado da Arte, seja em nível de Brasil ou Internacional. É preciso avançar em busca de uma práxis informacional, em que teoria e ação caminhem juntas em busca de uma complexidade social e da transversalidade cultural.

A isso, é possível observar, como exemplos, as pesquisas comunicadas na International Society for Knowledge Organization (ISKO) - Capítulos Brasil e Espanha/Portugal - e os periódicos científicos da área, que têm produzido e apresentado comunicações direcionadas ao campo científico da Ciência da Informação com ênfase a Representação do Conhecimento. Por isso, é visto que o campo da Representação do Conhecimento começou a perceber a importância de abrir espaço para pensar iniciativas investigativas, com propósito de impulsionar a Dimensão Social da Ciência da Informação no contexto da Organização do Conhecimento.

Em virtude disso, é relevante considerar o pensamento de García-Gutiérrez (2006, p. 103). Segundo ele, é preciso caminhar em direção a um ecossistema informacional capaz de identificar os "cientificamente os favelados ${ }^{3}$ ", ou seja, aqueles e aquelas que estão imersos em um profundo estágio de Vulnerabilidade Sociocultural.

Fazer isso significa "acolher o conhecimento excluído, devolvendo-lhe a legitimidade negada pelos processos convencionais de reconhecimento e ordenação" (GARCÍA-GUTIÉRREZ, 2006, p. 103).

3 O conceito de "favelados" aqui é utilizado como sinônimo de "marginalizados" ou "excluídos". 
Considerando estes aspectos, de maneira orgânica, tem ocorrido uma mobilização recente ao campo, proporcionando contribuições que vislumbram saídas teóricas e metodológicas a partir de importantes periódicos científicos brasileiros.

No âmbito da Revista Informação \& Informação, no ano de 2017, por exemplo, foi produzido um número temático que traz como Dossiê, a relação entre "organização do conhecimento e gênero".

Dele, é possível observar o posicionamento de Guimarães (2017, p. 92), onde é sinalizado que na:

[...] dimensão cultural, os maiores desafios se colocam no sentido de se evitar o preconceito, o proselitismo e as dominações culturais de modo a promover a compatibilização entre a necessidade de uma comunicação global e o respeito às questões locais (ANDERSEN; SKOUVIG, 2017 apud GUIMARÃES, 2017, p. 92).

Nesta mesma linha de pensamento, Saldanha e Souza (2017, p. 16), sugeriram uma Organização do Conhecimento por meio de uma reflexão que inclua a "categoria social", permitindo que "por essa lente podemos reunir o grupo de questionamentos e de denúncias sobre a função histórica de uma Organização do Conhecimento para seu contexto social". Isso, em essência, pode contribuir para que o campo e o Profissional da Informação possam ver além de uma imagem autorreflexiva. Será permitido observar entre os explícitos e os implícitos, os ditos e os não ditos da informação.

Por isso, Antonio García-Gutiérrez compreende: "Eu vou dizer na velha língua da rebelião: já que a ocupação cultural e digital já é um fato inevitável, vamos estabelecer uma barricada de consenso que possa permitir, na sua retaguarda, continuar desenvolvendo e retornando a dissidência" (GARCÍA-GUTIÉRREZ, 2018a, p. 112)4. Isso certamente levará a uma nova ecologia informacional, permitindo um ecossistema do conhecimento baseado na complexidade e transversalidade intelectual.

Moura (2018, p. 119) aproveita e sinaliza que "ampliaram-se as abordagens que reivindicam uma virada transversal e interseccional na base dos dispositivos estruturados no contexto da organização do conhecimento". Isso ocorre tendo em vista que nesta

[...] configuração do capitalismo global tornou-se mais visível à coexistência de diferentes formas de produção de conhecimento e a

4 Tradução de Gustavo Silva Saldanha. 
participação de diferentes atores em sua produção. De forma complexa e diversificada, novas formas de organização do conhecimento são integradas em torno dos atores, como a sociedade, o mercado e a universidade (MORA; ARIAS, 2018, p. 204).

O campo da Organização do Conhecimento, através de seus profissionais "se vê na obrigação de compreender ou, ao menos, de aceitar os relativismos e as mobilidades culturais, é o princípio da contradição" (SALES, 2018, p. 263). Desse processo, tem-se a possibilidade de viabilizar Reflexões Críticas, Construtivistas, Interseccionais e Dialéticas, com vistas a buscar um diálogo e um entendimento Coletivo, Plural e Horizontal.

É por este motivo que se busca uma Representação Sociocultural do Conhecimento, especialmente por considerar a sua importância como mediadora estratégica e relevante para responder aos Dilemas Sociais e Informacionais vigentes (GAUDÊNCIO; ALBUQUERQUE; CÔRTES, 2018; GAUDÊNCIO, 2020) ao campo, dialogando diretamente com o que García-Gutiérrez (1998, tradução nossa) denomina de Epistemografia.

Para García-Gutiérrez (1998, p. 15, tradução nossa), o conceito de Epistemografia "foi cuidadosamente escolhido para representar todo esse mundo de confluências". Ainda segundo o autor, o conceito de Epistemografia ou da Epistemografia Interativa, como prefere denominá-la, incorpora "uma dimensão sociocultural, ética e política, em suma, crítico-pós-moderna" (GARCÍA-GUTIÉRREZ, 2006, p. 104).

Portanto, este cenário de reflexão Paradigmática, seja de crise ou em direção a uma mudança no âmbito do campo da Organização do Conhecimento, apenas ocorre por se perceber que a comunidade científica começa a compreender que existem hiatos informacionais que demandam questionamentos.

Por esse motivo, diante da contemporaneidade, é salutar questionar as distintas contradições e antíteses existentes, que para Olson ${ }^{5}$ (2018, p. 492, tradução nossa) "ao questionar os fundamentos, podemos revelar suposições não justificadas e mudar nossas práticas [...]", elevando, assim, o nível de profundidade, maturidade e inclusão teórica e metodológica.

\footnotetext{
${ }^{5}$ Entrevista realizada por Daniel Martinez-Ávila, Rosali Fernandez de Souza, Gustavo Silva Saldanha e Luana Sales em 31 ago. 2018 por meio do periódico Liinc em Revista.
} 


\subsection{DESCLASSIFICAÇÃo do CONHECIMENTO}

Trata-se aqui da reflexão que tem como ponto de partida o conceito forjado por Antonio García-Gutiérrez, que é o de "Desclassificar" o conhecimento.

Os valores expressos nessa concepção caminham na direção de refletir sobre a importância de uma Reclassificação do Conhecimento, ou seja, de incluir a Diversidade e o Pluralismo Sociocultural na dinâmica classificatória. Antonio GarcíaGutiérrez observa que:

A desclassificação não deixa de classificar e organizar, [...]. Instâncias desclassificadas têm oportunidades iguais porque o sistema de desclassificação não prescreve ou proscreve, mas sugere, não hierarquiza, mas complementa, não subordina, mas se aproxima, não fecha, mas abre significado, nunca termina instâncias, mas busca incessantemente posições e oposições para alimentá-las, não exclui, mas inclui, não apaga, mas acumula, não explica, mas mostra, nunca interrompe seu trânsito porque acompanha o trânsito do conhecimento (GARCÍA-GUTIERREZ, 2011a, p. 202, tradução nossa).

Valorizando este entendimento e considerando que a ideia de Desclassificação passa por uma retomada e ressignificação epistemológica e reflexiva da forma como o conhecimento foi historicamente efetivado e construído, García-Gutiérrez (2020, p. 86, tradução nossa), direciona o pesquisador a perceber que

O que a desclassificação propõe é que, para construir o pensamento sobre qualquer assunto e especialmente sobre as próprias contradições, alguns ou muitos dos argumentos e procedimentos utilizados podem e devem ser contraditórios, ou seja, teríamos que abandonar a consistência (tomando uma posição paraconsciente) para alcançar o pensamento desclassificado do mundo organizado pela classificação.

Essa ideia transcende e pode perpassar e se aplicar a todo e qualquer SOC instituído ou que possa vir a ser configurado. Dito isso, a Desclassificação envolve basicamente a introdução do Pluralismo na lógica central da Classificação (GARCíAGUTIÉRREZ, 2011a, GARCÍA-GUTIÉRREZ, 2011b).

Para esta investigação, em primeiro lugar, busca-se ressignificar para que se permita contribuir para um "significado alternativo" e, em segundo, para provocar um posicionamento derivado diante dos SOCs tradicionais. Tem-se a possibilidade de pensar o processo de Representação do Conhecimento para além do que está estabelecido pelos rígidos, morosos e centralizadores tipos de sistemas.

Vimos que a classificação convencional é baseada em uma lógica dicotômica subjacente da qual emergem hierarquias e associações, ancoradas a uma visão particular e indiferentes ao pluralismo cultural, 
ideológico e cognitivo. A dicotomia seria, portanto, uma frente aberta para a ação de desclassificação (GARCÍA-GUTIÉRREZ, 2014b, p. 20, tradução nossa).

Mas, com a Desclassificação, esse processo hierárquico é ressignificado e reengendrado, ganhando um novo papel. Ele passa a atuar para oportunizar a horizontalidade, a rede de conexões culturais e semânticas. Assim, é perdido o:

[...] seu papel dominante na definição da estrutura para prevalecer como método de construção apenas em primeira instância, ou seja, para servir de andaime para o edifício horizontal. Uma vez construída na macroestrutura, a lógica hierárquica é transformada em uma microestrutura de qualquer outro relacionamento na linguagem e até se torna dependente da estrutura associativa (GARCÍA-GUTIÉRREZ, 1998, p. 14, tradução nossa).

Desclassificar é, aqui, sinônimo de desordenar para reordenar. De "suspender para ceder" às demandas latentes; é uma prática Dialética de desconstruir para construir a partir das contradições instauradas; é o ato revolucionário de questionar, criticar e propor saídas ao conhecimento objetivado, institucionalizado. Portanto, "[...] a desclassificação não deve ser ativada a fim de quebrar identidade ou cultura, mas simplesmente para fornecer uma consciência de ruptura, uma opção de abrir, misturar, interromper, [...] subverter qualquer dominação simbólica ou fechamento conceitual [...]" (GARCÍA-GUTIÉRREZ, 2018b, p. 1553, tradução nossa).

Desclassificar é a possibilidade de realizar uma Representação Sociocultural do Conhecimento, capaz de incluir a "ralé", "os marginalizados" e a "periferia" silenciada dentro dos SOCs. É ainda um movimento de transformação da forma como se pode organizar a vida e a sociedade.

Por isso, o conceito de "desclassificar" não surge como sinônimo para rechaçar, refutar ou negar o modelo clássico da Classificação enquanto disciplina do processo de Representação e Organização do Conhecimento, mas é, em essência, um fenômeno Investigativo Alternativo e Plural, de influência Dialética, Interseccional, Construtivista e Crítica, que se manifesta para questionar e propor saídas à forma como são estabelecidos Regimes Informacionais Dominantes dos SOCs tradicionais.

Segundo García-Gutiérrez nas palavras de Llorente (2008, p. 514) "Nós sabemos através de uma ação classificadora". Mas "classificar" também significa "ocultar o conhecimento". Como é possível, então, que nosso conhecimento seja o

\footnotetext{
${ }^{6}$ Da Resenha: GARCÍA-GUTIÉRREZ, A. Desclasificados: pluralismo lógico y violencia de la clasificación. Barcelona: Anthropos, 2007.
} 
alimento de nossa ignorância?” Na acepção de García-Gutiérrez (2014a, p. 2, tradução nossa):

Como arma de dominação, a classificação sempre acompanhou os projetos de colonização territorial e, sobretudo, cultural e cognitiva, e esteve na sala dos fundos de inúmeros atos de violência simbólica atingindo seu clímax paranoico na ideologia e nos arquivos classificados $^{7}$ do nazismo.

Por isso, as "práticas sociais, políticas e discursivas levam a repensar a relação entre o social e as representações que o refletem ou o camuflam" (MORAES; ARCELLO, 2000, p. 8).

Se, por um lado, o Profissional da Informação tem o papel de representar com vistas a uma recuperação possível, por outro, também assume o perigoso papel de silenciar grupos sociais ou categorias do conhecimento da sociedade.

Partindo dessa tônica, é preciso valorizar o processo de Representação do Conhecimento, garantindo, no seu ato, o respeito, à dignidade da pessoa humana $\mathrm{e}$ seus direitos fundamentais inerentes a cada grupo social.

É por este motivo que Ben Christensen, ao escrever o texto intitulado Minorization vs. Universalization: Lesbianism and Male Homosexuality in LCSH and $\angle C C^{8}$, chega à seguinte conclusão:

Embora a terminologia usada nos planejamentos de classificação não seja tão visível para o usuário final quanto os cabeçalhos dos assuntos, os preconceitos podem ser igualmente visíveis. Ao escolher essa terminologia e seu lugar na hierarquia, devemos ter em mente os diferentes grupos de pessoas que esses termos representam, sejam homossexuais ou heterossexuais, gays ou lésbicas. Também devemos ter em mente que as pessoas que compõem cada um desses grupos podem ter apenas mais do que orientação sexual em comum, o que significa que os indivíduos variarão muito na maneira como desejam ser representados - como partes invisíveis de um todo unificado ou tão visível. São minorias em uma multidão fraturada. Manter-se atualizado com as conotações atuais e o uso de vários termos não garantirá a satisfação de todos, pois não há como negar que é impossível, mas nos permitirá classificar e descrever conceitos de maneira consistente com o uso atual e com o maior respeito possível para as várias pessoas que esses termos descrevem (CHRISTENSEN, 2008, p. 237-238, tradução nossa).

\footnotetext{
7 Os arquivos classificados também assumem a função de arquivos secretos e sigilosos.

8 Cf. Christensen (2008, p. 237-238, tradução nossa).
} 
Evidentemente que Ben Christensen faz uma opção ao recorte do seu objeto, mas é nítido que o debate irá se aplicar a toda e qualquer forma de grupos Socioculturais minorizados, implicando nos mais distintos tipos de exclusão.

Basta olhar em volta: discriminação, injustiça, desigualdade, destruição, exploração desenfreada de recursos, [...], conformismo, não solidariedade, dissolução da ética, cinismo, egoísmo do egoísmo, egoísmo do altruísta, dogmatismo, relativismo, absolutismo, barbárie, barbárie do absolutista e barbárie do relativista. As misérias não param por aí. O catálogo [...], como você pode imaginar, é muito mais extenso (GARCÍA-GUTIÉRREZ, 2014a, p. 5, tradução nossa).

O processo de Exclusão Sociocultural do conhecimento pode se manifestar de diversas formas, uma delas é a de classificar o ser humano como inferior, como menor, como grupo minorizado. Notadamente, vale salientar que o ato de minorizar um grupo social é uma estratégia para inferiorizá-lo e deixá-lo fora dos limites estatísticos e estatais e, consequentemente, das suas políticas públicas informacionais.

Outrora, a Desclassificação vai caminhar justamente em sentido oposto ao da classificação convencional, pois vai tentar entender como os (as) marginalizados (as) ficam de fora da Representação do Conhecimento, permitindo que dossiês terminológicos possam ser construídos para subsidiar a criação de Agendas de Políticas de Informação com intuito de atenuar os efeitos dos Buracos Informacionais, no sentido de revelar os hiatos, as fraturas, as cisões que ofuscam a forma como o conhecimento é representado, são evidentes e nitidamente visíveis nos SOCs tradicionais. Eles silenciam e escondem grupos sociais reveladores de conhecimento, tanto em grandes centros urbanos, nas periferias, como em áreas campesinas.

Um dos motivos para existência de Buracos Informacionais nos SOCs tradicionais é o fato de que a "cultura, identidade, memória, racionalidade, informação, conhecimento e sua classificação seriam instâncias colonizadas que disseminam a colonização" (GARCÍA-GUTIÉRREZ, 2014b, p. 9, tradução nossa).

Os SOCs tradicionais são reguladores e responsáveis por constantes violências simbólicas, seja na construção dos próprios sistemas, que são desenvolvidos pelas entidades de classe, instituições ou pelos (as) operadores (as) da informação que os ratificam, gerenciam e consomem como verdade absoluta. Percebe-se que, no momento de realizar as suas tarefas de indexação em sistemas de informação, na construção da catalogação na fonte ou, ainda, na forma de entender 
quem deve e porque devem ser incluídos os termos por meio dos metadados dentro de uma determinada base de dados, também são nítidas as formas como profissionais se comprometem dogmaticamente para fazer valer as construções cristalizadas.

O Profissional da Informação está soterrado em meio a um poder simbólico, tendendo a reproduzir o senso comum da cultura dominante. Este cenário, que muitas vezes é dogmático e totalitário, faz do organizador do conhecimento um operário burocrático (GARCÍA-GUTIÉRREZ, 2014a, tradução nossa). Isso retira do profissional a possibilidade de um cenário de emancipação, empurrando-o, potencialmente, direta ou indiretamente, aos "porões" da alienação e da manipulação da informação.

Para suplantar cenários e marcas históricas é preciso evidenciar e investir em um cenário transcultural, onde sejam oportunizadas Construções Socioculturais alinhadas com a Alteridade, que refere-se ao estudo das "[...] diferenças entre várias culturas e etnias. É o estudo das diferenças e o estudo do outro, ela assume um papel essencial [...]" na sociedade (MENEZES, 2021) ${ }^{9}$, a horizontalidade e uma rede saberes calcada na Pluralidade. Nessa linha de pensamento, García-Gutiérrez (2013, p. 109, tradução nossa), entende que:

Transcultura é a própria troca acelerada e incessante de valores, categorias e universos simbólicos, cada vez mais desenraizados de suas matrizes culturais originais que supõe a quebra de visões de mundo e tradições verticais, já em dissolução. Remove as antigas classificações hierárquicas e as mitologias do mundo, impregnadas na linguagem que as cria e as mantém, mas estabelece uma estrutura horizontal unificadora que submete de forma igualitária aos sujeitos. A transcultura extingue valores práticos ancestrais, alguns de valor incalculável para a diversidade e outros baseados na infâmia, mas também deve ser visto como um novo espaço que nos permite repensar, abolir ou reverter conceitos, arranjos, fronteiras, hegemonias, dependências, essencialismos, anestesias.

Evidentemente que a investigação não caminha para excluir o estabelecido, mas para abrir novas frentes de atuação e de ocupação territorial na geografia informacional dos SOCs. Portanto, o interesse aqui se pauta na necessidade de Reconexão com as formas de Representar o Conhecimento, sem a disposição anárquica de suplantar ou negar os modelos em vigência. É evidente que esta pesquisa assume o papel de contribuir para promoção de um debate mais amplo em torno do campo, pois para que se possa construir algo efetivamente alternativo que

${ }^{9}$ Cf. MENEZES, P. Alteridade. [S.I.]: Significados, 2021. Disponível em: https://www.significados.com.br/alteridade. Acesso em: 11 dez. 2021. 
inclua a sociedade nas suas mais complexas formatações, é mister trasladar a maneira como se pensa e se organiza o conhecimento da civilização por meio dos seus compêndios e sistemas de códigos pouco amigáveis.

\subsection{DescolonizaÇÃo do SABER}

Para que seja favorecido um cenário de Reconexão do Saber com a vida, é oportuno que existam as condições de questionamento dos modelos dominantes do conhecimento para que se permita construir a crítica necessária para apresentar propostas alternativas ao que está estabelecido. É nesse limiar que se possibilita a ideia de promover a Descolonização do Saber tendo em vista contribuir para visibilizar, reconhecer a voz dos subalternizados.

A Descolonização surge como uma corrente de pensamento e, dentre suas reflexões, está a busca de compreender para romper com a complexidade do Colonialismo e do Pós-colonialismo e, a partir daí, idealizar saídas contrahegemônicas e emancipatórias que possam incluir as pessoas imersas na sociedade: os "subalternizados", ou seja, aquelas pessoas que estão à margem da sociedade.

Para Piza e Pansarelli (2012, p. 30-31), ao se tratar dos processos de Descolonização, se crê que estes

[...] se iniciaram, historicamente, como um processo de libertação das colônias e formação de Estados-nações independentes, hoje, devem continuar com a libertação de uma colonização epistêmica que, se efetivada, abriria espaço para a concepção de outra razão, de outra racionalidade. A descolonização colocaria fim a um processo histórico de implantação de dado tipo de poder.

Segundo o pensador português Boaventura de Sousa Santos, o debate sobre a Descolonização "carrega sobre os ombros um longo passado de relações desiguais entre as culturas metropolitanas e coloniais" (SANTOS, 2018b, p. 284). Ao buscar refletir os países do Sul (subdesenvolvidos) em relação aos do Norte (desenvolvidos), percebem-se dois tipos de desigualdades: a externa - países pobres versus países ricos - e a interna - subalternizada versus classe alta. São abismos de fora para dentro e de dentro para fora.

Por esse motivo, uma das razões da Descolonização é ser uma potência do Paradigma Emergente (SANTOS, 2018a) para poder contribuir com uma Revolução Paradigmática e fazer com que o "excluído (a)" possa ser introduzido no processo de 
construção do conhecimento e, consequentemente, colocar-se em posição de contar a sua própria narrativa.

É, portanto, preciso vislumbrar a Descolonização como "[...] uma segunda independência que finalmente rompa com os vínculos eurocêntricos que condicionaram os processos de desenvolvimento [...]" (SANTOS, 2018c, p. 245). Diante disso, para se falar de Descolonização, se faz necessário contar a história dos "vencidos", das pessoas socialmente vulneráveis que sofrem altos índices de desigualdades sociais. Mas, quem está contando a história? Segundo Martins e Côrtez (2019, p. 174), é preciso questionar: Quem demarca o lugar de fala?

Esse questionamento vai levar a uma resposta possível, que na maioria das vezes, o lugar de fala estará atrelado ao poder simbólico institucionalizado e aos níveis de preconceitos que são estruturais (ALMEIDA, 2019) e foram historicamente estabelecidos pela classe dominante, que, por sua vez, produz opressão e aprofunda a tônica dos subalternizados. Para romper com esta realidade é preciso "promover uma multiplicidade de vozes [...], acima de tudo, [...] quebrar com o discurso autorizado e único, que se pretende universal" (RIBEIRO, 2019, p. 48).

Em outra frente, mas complementar ao que fora mencionado, Boaventura de Sousa Santos, em entrevista ao Jornal Le Monde Diplomatique Brasil'10 (SANTOS, 2018d), dá o seguinte exemplo: quem tem feito a história dos "vencidos" no Brasil são os rappers. Eles contam o que não está nos livros de história. Boaventura vai além, dizendo que os "vencidos" não estão nos livros. E por quê? O currículo é feito por "vencedores", é feito por brancos e para brancos. Eles são os protagonistas.

É preciso afirmar que o rap não é o único caso de expressão de resistência, mas o que se percebe é que as iniciativas que emergem vêm de pessoas que estão na Marginalidade Sociocultural, de grupos das periferias ou de estudiosos (as) que provocam a reflexão, mas que ainda são uma pequena parcela da população brasileira.

Trazendo essa observação para Ciência da Informação, surge a indagação: quem produz os SOCs? Como é feita a sua representação? Quem foi contemplado? Quem são os grupos de domínio que representam e são representados? De que forma grupos como os negros, mulheres, idosos, os povos tradicionais, os saberes

\footnotetext{
10 Entrevista realizada por Guilherme Henrique e Cristiano Navarro em 14 de set. de 2018. Disponível em: https://youtu.be/9MhE-OaBBss. Acesso em: 16 jun. 2020.
} 
populares, as pessoas em situação de rua, as pessoas com deficiências, a periferia, os jovens estão sendo representados? E estes grupos sociais, sujeitos de sua história, estão sendo chamados para discutir os SOCs? Os SOCs são feitos para quem?

Essas são algumas perguntas que precisam ser feitas diariamente e, além disso, ações devem ser viabilizadas para incluir a sociedade que historicamente vive em situação de Vulnerabilidade Sociocultural e Infoeconômica, pois "há um patrimônio, que irradia os (sic) saberes de povos historicamente discriminados, que permanece, em muitos casos, intacto, inabordável e inencontrável nos bancos de dados materiais e digitais" (BORGES, 2015, p. 176).

Para romper com esse cenário de sufocamento pela "normalização hegemônica" (MARTINS; CÔRTEZ, 2019, p. 174) do saber às "minorias" que são desprestigiadas, é necessária uma profunda transformação do Estado. É preciso a configuração de um novo senso comum, cuja centralidade esteja em uma mudança de mentalidade que viabilize uma Virada Cognitiva e Paradigmática.

Esse é um dos motivos pelos quais Gramsci (1982), na obra "Os Intelectuais e a organização da cultura", apontava ser preciso construir um novo modelo de senso comum e de intelectualidade.

Na mesma linha de pensamento está Boaventura de Sousa Santos (2010, p. 88), ao observar que dentre as formas de conhecimento, a "mais importante de todas é o conhecimento do senso comum, o conhecimento vulgar e prático com que no quotidiano (sic) orientamos as nossas acções (sic) e damos sentido a nossa vida".

Contudo, salienta-se que, ao tratar do senso comum, defende-se que as distintas vozes sejam ouvidas e consideradas ferramentas potenciais às pautas da agenda científica, para que, com isso, a sociedade possa reverberar todos os modos de saberes, sem uma "verdade" universal, como buscam correntes de pensamento como o Positivismo e o Determinismo científico, por exemplo.

É no âmbito do senso comum que o conhecimento inicia e termina, por isso posições investigativas não deveriam pensar a pesquisa científica apenas na relação Sujeito/Objeto, mas sim Sujeito/Sujeito. O objeto, neste contexto de pensar a ciência de forma Descolonizada, é na verdade Sujeito de sua própria história.

Torna-se primaz uma Virada Paradigmática, uma Revolução Sociocultural e Infoeconômica de longo prazo, caso contrário, será cada vez mais difícil romper com um Colonialismo estrutural, metamorfoseado na forma de Pós-colonialismo de 
"desenvolvimento", que continua em vigência e se faz presente no Século XXI, aprofundando os mais altos níveis de violências simbólicas, como o preconceito racial, de regionalidade, de xenofobia, de padrão de beleza, de classe social, de gênero, entre outros.

Para tentar superar a realidade conjuntural centenária, é pertinente abrir espaço para uma Ecologia dos Saberes (SANTOS, 2006), onde as mais distintas especificidades da sociedade e tipos de saberes possam ser incluídas nos debates e nas políticas de Estado.

O cerne da Ecologia de Saberes é superar a lógica da monocultura do conhecimento dominante e fazer com que esse conhecimento aceito e oriundo exclusivamente da cultura elitista seja questionado "pela identificação de outros conhecimentos e outros critérios de rigor que operem com credibilidade em contextos e práticas sociais declarados [...]" (SANTOS, 2006, p. 78-79).

Em linhas gerais, a Ecologia de Saberes, viabilizada pela Descolonização enquanto potência epistemológica de empoderamento aos grupos marginalizados, valorizará e provocará o debate de incluir na pauta científica e social o conhecimento que advém de pessoas, grupos ou movimentos, hoje considerados como "subalternizados" do saber, como: das Benzedeiras, das Rezadeiras, das Curandeiras, dos Rappers, dos Pescadores (Caiçaras), dos Quilombolas, dos Ribeirinhos, dos Cordelistas, dos Contadores de Histórias, dos Ritos Afro-brasileiros, do Feminismo, das Parteiras, dos Grafiteiros, dos Ciganos, dos Artistas de Rua, dos Idosos, dos Presidiários, das Pastorais Sociais Progressistas, dos Trabalhadores Assalariados, dos Desempregados, das Pessoas com Deficiências, do Movimento Negro, do Movimento LGBTQI+, dentre outros.

Ainda assim, é necessário questionar: Como estão sendo contadas as histórias que representam esse povo? Quando esses construtos do conhecimento, oriundos dessas pessoas, grupos ou movimentos sociais, estão sendo aceitos pela sociedade, legitimados pela academia e transformados em ações governamentais do Estado?

Por esse motivo, o conhecimento científico deve ser aglutinador de saberes e assumir um papel de ressignificação e de um instrumento reformador. Para Boaventura de Sousa Santos $\left(2010,2013^{11}\right)$, é preciso "des-pensar" para que se

11 Informações retiradas de vídeo publicado em 2014 em evento da Universidad Autónoma de la Ciudad de México (UACM), onde Boaventura de Sousa Santos é acompanhado pelo pesquisador Enrique 
permita pensar e, pensando por meio de uma nova consciência, permitir incluir. É preciso pensar a universidade de fora para dentro, trazendo a Pluralidade Cultural e toda a sua complexidade para o "seio" da academia.

Com isso, se entende a importância de remodelar a sociedade para instituir uma forma alternativa de pensamento, onde as mais distintas possibilidades de saberes possam ser incorporadas, e assim facilitar a compreensão de que os "oprimidos" do saber deveriam ter a oportunidade de contar a sua própria história, escrever a sua narrativa. O Século XXI precisa caminhar para abrir as janelas do conhecimento a todos (as), que são produtores de conteúdo e, assim, potencializar a verdade dos "marginalizados" do conhecimento. Os diversos rostos da multiculturalidade presente na sociedade precisam compor a tessitura do mundo do conhecimento.

Não havendo a inclusão das narrativas dos "vencidos" e oportunizando o "lugar de fala" (MARTINS; CÔRTEZ, 2019, p. 174), será impossível falar de identidade cultural em sua totalidade. Se não houver incorporação da academia e aceitação do Estado, dificilmente existirão políticas públicas inclusivas e consequentemente os casos supracitados continuarão invisíveis, podendo impactar no aprofundamento dos mais distintos níveis de preconceitos e desigualdades sociais.

Com isso, vê-se que o Pensamento Crítico e Reflexivo por meio da Descolonização do Saber, não só é importante e benéfico para a Ciência, como também para a Sociedade. Esse pensamento permite entender a ideia de construção social da realidade numa lógica mais aproximativa e interseccional. É, ainda, uma disciplina investigativa, intimamente próxima ao que se tem pensado e expressado sobre a proposta de Desclassificação do Conhecimento, demonstrando mais uma forte comunhão teórica entre os campos do saber.

Por fim, se compreende o quanto é importante a presença do (a) Profissional da Informação, como um sujeito Socioinformacional privilegiado e capaz de contribuir com o papel de uma Ciência da Informação que busque reduzir os níveis de desigualdades sociais latentes e que ofuscam a promoção da equidade do saber a todas as pessoas, assim como de tornar público o conhecimento que é produzido pela sociedade, independentemente de quem seja o (a) produtor (a) de conteúdo.

Dussel. Este vídeo tem como tema: Descolonización epistemológica desde el Sur. Disponível em: https://youtu.be/hb1yUnf8TQU. Acesso em: 18 jun. 2020. 


\section{CONSIDERAÇÕES FINAIS}

Este texto foi parte do resultado de pesquisa doutoral, que propôs a constituição de uma proposta de Representação Sociocultural do Conhecimento (RSC) para tratar a complexidade de Objetos Digitais com características Culturais e influências Sociais que estão presentes em Mídias Sociais.

Ao que tange a este recorte teórico, percebeu-se a RSC como uma proposta que ganha sentido a partir de sua força Dialética e enfoque Sociocultural, seja no pensar, no questionar ou no ato de sugerir algo a partir dos Construtos da Desclassificação do Conhecimento e da Descolonização do Saber, estabelecidos pelos Campos Científicos envolvidos nesta investigação.

A pesquisa revelou que, para atuar com a RSC, antecipadamente, é importante se despir de qualquer tipo de pensamento incluso no guarda-chuvas dominantes, fazendo-se mister um Repensar em torno de Teorias, Métodos e Práticas Informacionais Tradicionais, pois, para que seja possível pensar sob a ótica e lógica da Desclassificação e da Descolonização do Conhecimento, é preciso de uma Reconexão Mental, uma Reprogramação Cognitiva e uma Ressignificação da Vivência em busca de um movimento que oportunize um perceber Dialético, Crítico, Construtivista e Interseccional.

Constatou-se que ainda existe uma singular carência por mais investimentos investigativos Interdisciplinares direcionados ao processo de Desclassificação e Descolonização do Conhecimento, com vistas a mostrar ao Profissional da Informação que são percebidas possibilidades alternativas de atuação, seja no âmbito acadêmico, de mercado ou diante da sociedade. Dito isso, recomenda-se que sejam feitos futuros estudos no sentido de que esta pesquisa possa contribuir e motivar posteriores desdobramentos, inclusive no desenvolvimento de propostas metodológicas que levem a práticas alternativas dentro do Domínio da Organização e Representação da Informação e do Conhecimento.

É por esse motivo que esta pesquisa se mostrou como uma Investigação Interdisciplinar, à medida que os questionamentos e as reflexões da Ciência da Informação encontraram os da Sociologia e resultaram em um Repensar Epistemológico, de Posicionamento Socioinformacional e de um Reposicionamento Sociopolítico e Sociocultural. 
Portanto, espera-se então que esta Construção Teórica possa contribuir para o fortalecimento do Campo em questão, com ênfase ao processo de RSC, como também, aproximar este debate de outros Campos do Saber, permitindo que esta investigação possa indagar um Repensar aos Modelos Cristalizados na Graduação e na Pós-Graduação da Biblioteconomia e na Ciência da Informação Brasileira.

\section{REFERÊNCIAS}

ALBUQUERQUE, M. E. B. C. Literatura popular de cordel: dos ciclos temáticos à classificação bibliográfica. 2011. 314 f. Tese (Doutorado em Letras) - Universidade Federal da Paraíba, João Pessoa, 2011. Disponível em: https://bit.ly/3nBMjHZ. Acesso em: 28 abr. 2021.

ALMEIDA, S. Racismo estrutural. São Paulo: Pólen, 2019. (Feminismos plurais).

BORGES, R. O Arquivo e a organização do dito e do visível: armazenamento e circulação dos saberes silenciados nas tramas hipertextuais. Revista da ABPN, v. 7, n. 17, p. 163-189, jul./out. 2015. Disponível em: https://bit.ly/2Z4IP5V. Acesso em: 23 jun. 2021.

CARLAN, E.; MEDEIROS, M. B. B. Sistemas de Organização do Conhecimento na visão da Ciência da Informação. RICl: Revista Ibero-americana de Ciência da Informação, Brasília, v. 4, n. 2, p. 53-73, ago./dez. 2011. Disponível em: https://bit.ly/33YPgsw. Acesso em: 30 mar. 2021.

CAPURRO, R. Epistemologia e ciência da informação. In: ENCONTRO NACIONAL DE PESQUISA EM CIÊNCIA DA INFORMAÇÃO (ENANCIB), 5., 2003, Belo Horizonte. Anais [...] Belo Horizonte: ANCIB, 2003. Disponível em: https://bit.ly/2qQTUZB. Acesso em: 11 dez. 2021.

CHRISTENSEN, B. Minorization vs. universalization: lesbianismo and homosexuality in LCSH and LCC. Knowl. Org., v. 35, n. 4, p. 229-238, 2008. Disponível em: https://bit.ly/2XCQU1L. Acesso em: 14 abr. 2021.

COSTA, V. G.; NASCIMENTO, J. A. S. O Conceito de favelas e assemelhandos sob o olhar do IBGE, das prefeituras do Brasil e da ONU. In: ENCONTRO DE GEÓGRAFOS DA AMÉRICA LATINA, 10., 2005, São Paulo. Anais [...]. São Paulo: USP, 2005. Disponível em: https://bit.ly/2XsCQHC. Acesso em: 06 jun. 2021.

\section{GARCÍA-GUTIÉRREZ, A. Principios de lenguaje epistemográfico: la} representación del conocimiento sobre patrimonio histórico andaluz. Sevilla; Granada: Consejería de Cultura de la Juntade Andalucía, Instituto Andaluz del Patrimonio histórico; Comares, 1998.

GARCÍA-GUTIÉRREZ, A. Cientificamente favelados: uma visão crítica do conhecimento a partir da epistemografia. TransInformação, Campinas, v. 18, n. 2, 
p. 103-112, maio/ago. 2006. Disponível em: http://ref.scielo.org/dhcptm. Acesso em: 12 mar. 2021.

GARCIA-GUTIERREZ, A. Desclassification in knowledge organization: a postepistemological essay. TransInformação, Campinas, v. 23, n. 1, p. 05-

14, apr. 2011a. Disponível em: https://bit.ly/2znBHr4. Acesso em: 25 abr. 2021.

GARCÍA-GUTIÉRREZ, A. Epistemología de la documentación. Barcelona, Espanha: Stonberg Editorial, 2011b.

GARCÍA-GUTIÉRREZ, A. La Organización del conocimiento desde la perspectiva Pós-colonial: itinerarios de la paraconsistencia. Perspectivas em Ciência da Informação, Belo Horizonte, v. 18, n. 4, p. 93-111, out./dez. 2013. Disponível em: https://bit.ly/3cbh5kx. Acesso em: 25 abr. 2021.

GARCÍA-GUTIÉRREZ, A. La Organización del conocimiento en el nuevo orden transcultural: del totalitarismo a la desclasificación (la razón como creencia y la oc como burocracia). Brazilian Journal of Information Science: Research Trends, Marília, v. 8, n. 1/2, dez. 2014a. Disponível em: https://bit.ly/352RcR0. Acesso em: 25 abr. 2021.

GARCÍA-GUTIÉRREZ, A. La Organización del conocimiento en el nuevo orden transcultural: del totalitarismo a la desclasificación (obstáculos epistémicos, regencia de la transcultura y desclasificación). Brazilian Journal of Information Science:

Research Trends, Marília, v. 8, n. 1/2, dez. 2014b. Disponível em: https://bit.ly/2VSYG50. Acesso em: 25 abr. 2021.

GARCÍA-GUTIÉRREZ, A. Por uma economia política da organização do conhecimento. Liinc em Revista, Rio de Janeiro, v. 14, n. 2, p. 109-117, nov. 2018 a. Tradução de Gustavo Silva Saldanha. Disponível em: https://bit.ly/2O3AIQi. Acesso em: 14 mar. 2021.

GARCÍA-GUTIÉRREZ, A. En Pedazos: el sentido de la desclassificación. Madrid: ACCI Ediciones, 2018b. E-book.

GARCÍA-GUTIÉRREZ, A. A Ojos de la arena: ejercicios de desclasificación. Madrid: ACCI Ediciones, 2020. E-book.

GAUDÊNCIO, M. S. Representação Sociocultural do Conhecimento: contribuição teórico-metodológica para o campo informacional. 2020. 196 f. Tese (Doutorado em Ciência da Informação) - Universidade Federal da Paraíba, João Pessoa, 2020. Disponível em: https://bit.ly/3xzm6ya. Acesso em: 28 abr. 2021.

GAUDÊNCIO, M.; ALBUQUERQUE, M. E. B. C.; CÔRTES, G. R. Expandindo o cosmos da representação social do conhecimento por meio da categorização de marcadores sociais da diferença. Liinc em Revista, Rio de Janeiro, v. 14, n. 2, p. 295-317, 2018. Disponível em: https://bit.ly/2RBDLmP. Acesso em: 8 jan. 2021.

GOMES, P. H. C.; EVANGELISTA, I. V.; MARTINEZ-ÁVILA, D.; GRÁCIO, M. C. C. A Dimensão Cultural da Organização do Conhecimento: análise das comunidades 
epistêmicas a partir dos congressos da ISKO-Brasil. [S.I.: s.n.], 2017. Disponível em: https://bit.ly/3glzUAE. Acesso em: 8 jan. 2021.

GRAMSCI, A. Os Intelectuais e a organização da cultura. 2. ed. Rio de Janeiro: Civilização Brasileira, 1982. 244 p. (Coleção Perspectivas do Homem Série Filosofia, 48).

GUIMARÃES, J. A. C. Organização do conhecimento: passado, presente e futuro sob a perspectiva da ISKO. Informação \& Informação, Londrina, v. 22, n. 2, p. 8498, maio/ago. 2017. Disponível em: https://bit.ly/2HfkXoV. Acesso em: 13 mar. 2021.

HALBWACHS, M. A memória coletiva. Tradução de L. L. Schaffter. São Paulo: Vértice; Revista dos Tribunais, 1990.

HALL, S. A Identidade cultural na pós-modernidade. Rio de Janeiro: Lamparina, 2015.

HALL, S. Cultura e representação. Tradução de Daniel Miranda e William Oliveira. Rio de Janeiro: PUC-Rio, 2016.

LARA, M. L. G. Problemas da organização do conhecimento na contemporaneidade. In: CONGRESSO BRASILEIRO EM ORGANIZAÇÃO E REPRESENTAÇÃO DO CONHECIMENTO, 2., 2013, Rio de Janeiro. Anais [...]. Rio de Janeiro: ISKO-Brasil, 2013. Disponível em: https://bit.ly/2ttp8oc. Acesso em: 19 fev. 2021.

LARA, M. L. G.; MENDES, L. C. Referências socioculturais na organização do conhecimento. In: CONGRESSO BRASILEIRO EM ORGANIZAÇÃO E REPRESENTAÇÃO DO CONHECIMENTO, 4., 2017, Recife. Anais [...]. Recife: ISKO-Brasil, 2017. Disponível em: https://bit.ly/2ttp8oc. Acesso em: 11 mar. 2021.

LLORENTE, M. L. Desclassificados. Revista Científica de Información y Comunicación, v. 5, p. 514-517, 2008. Resenha. Disponível em: https://bit.ly/2ys9peK. Acesso em: 2 abr. 2021.

LÓPES-HUERTAZ, M. J. Panorama da pesquisa em OC em sua dimensão social, cultural e política (formação profissional, ética, cultural e identidade, contextos, sustentabilidade). In: CONGRESSO BRASILEIRO EM ORGANIZAÇÃO E REPRESENTAÇÃO DO CONHECIMENTO, 2., 2013, Rio de Janeiro. Anais [...]. Rio de Janeiro: ISKO-Brasil, 2013. Disponível em: https://bit.ly/2ttp8oc. Acesso em: 19 fev. 2021.

MARTINS, G. K.; CÔRTEZ, A Representação da informação e do conhecimento e as representações sociais: intersecções e limites. In: ALBUQUERQUE, M. E. B. C. MARTINS, G. K. MOTA, D. A. R. (org). Organização e representação da informação e do conhecimento: intersecções teórico-sociais. João Pessoa: Editora UFPB, 2019.

MENEZES, P. Alteridade. [S.I.]: Significados, 2021. Disponível em: https://www.significados.com.br/alteridade. Acesso em: 11 dez. 2021. 
MORA, R. P.; ARIAS, B. L. I. La organización del conocimiento como proceso: la movilización del conocimiento. Liinc em Revista, Rio de Janeiro, v. 14, n. 2, p. 199212, nov. 2018. Disponível em: https://bit.ly/2F10IHZ. Acesso em: 14 mar. 2021.

MORAES, A. F.; ARCELLO, E. N. O Conhecimento e sua representação. Informação \& Sociedade: Estudos, v. 10, n. 2, jan. 2000. Disponível em: https://bit.ly/2Vfnvc9. Acesso em: 16 abr. 2021.

MOURA, M. A. Organização social do conhecimento e performatividade de gênero: dispositivos, regimes de saber e relações de poder. Liinc em Revista, Rio de Janeiro, v. 14, n. 2, p. 118-135, nov. 2018. Disponível em: https://bit.ly/2HwhKjX. Acesso em: 14 mar. 2021.

NASCIMENTO, D. M. A Abordagem sócio-cultural da informação. Informação \& Sociedade: Estudos, João Pessoa, v. 16, n. 2, p. 25-35, jul./dez. 2006. Disponível em: https://bit.ly/2Hvedm8. Acesso em: 12 mar. 2021.

OLSON, H. Entrevista. Liinc em Revista, Rio de Janeiro, v. 14, n. 2, p. 491-494, nov. 2018. Entrevista realizada por Daniel Martinez-Ávila, Rosali Fernandez de Souza, Gustavo Silva Saldanha e Luana Sales em 31 ago. 2018. Disponível em: https://bit.ly/2FfNgRX. Acesso em: 14 mar. 2021.

PIZA, S. O.; PANSARELLI, D. Sobre a descolonização do conhecimento: a invenção de outras epistemologias. Estudos de Religião, v. 26, n. 43, p. 25-35, 2012. Disponível em: https://bit.ly/2BgoiC4. Acesso em: 16 jun. 2021.

RIBEIRO, D. Lugar de fala. São Paulo: Pólen, 2019. (Feminismos plurais). E-book.

SALDANHA, G. S.; SOUZA, R. F. Teoria barroca da organização do conhecimento: Emanuele Tesauro e o espelho turvo das tensões entre epistemologia, metodologia e sociedade. Informação \& Informação, Londrina, v. 22, n. 2, p. 11-32, maio/ago. 2017. Disponível em: https://bit.ly/2ChHL3d. Acesso em: 14 mar. 2021.

SALES, R. de. Devir-rizoma: tumulto na organização e representação do conhecimento. Liinc em Revista, Rio de Janeiro, v. 14, n. 2, p. 259-275, nov. 2018. Disponível em: https://bit.ly/2TAKLCm. Acesso em: 14 mar. 2021.

SANTOS, B. S. Conocer desde el Sur: para una cultura política emancipatória. Lima, Peru: Fondo Editorial de la Facultad de Ciencias Sociales, 2006. Disponível em: https://bit.ly/3fzKUwu. Acesso em: 16 fev. 2021.

SANTOS, B. S. Descolonizar el saber, reinventar el poder. Trilce: Montevideo, Uruguay, 2010. Disponível em: https://bit.ly/37HUZ7N. Acesso em: 18 jan. 2021.

SANTOS, B. S. Pela mão de Alice: o social e o político na pós-modernidade. 14. ed. São Paulo: Cortez, 2013.

SANTOS, B. S. Um discurso sobre as ciências. 8. ed. São Paulo: Cortez, 2018a.

SANTOS, B. S. Construindo as Epistemologias do Sul: para um pensamento 
alternativo de alternativas. Buenos Aires: CLACSO, 2018b. (Coleção Antologias do Pensamento Social Latino-americano e Caribenho, v. 1). Disponível em: https://bit.ly/2Y5m6qe. Acesso em: 16 jan. 2021.

SANTOS, B. S. Construindo as Epistemologias do Sul: para um pensamento alternativo de alternativas. Buenos Aires: CLACSO, 2018c. (Coleção Antologias do Pensamento Social Latino-americano e Caribenho, v. 2). Disponível em: https://bit.ly/2zDQ9vD. Acesso em: 16 jan. 2021.

SANTOS, B. S. Os três Ds de Boaventura: Descolonizar, Desmercantilizar e Democratizar. São Paulo: Diplomatique, 2018d. Entrevista realizada por Guilherme Henrique e Cristiano Navarro em 14 de set. de 2018. Disponível em: https://youtu.be/9MhE-OaBBss. Acesso em: 16 jan. 2021.

SOUSA, P. S.; TOLENTINO, V. S. Aspectos machistas na Organização do Conhecimento: a representação da mulher em instrumentos documentários. Informação \& Informação, Londrina, v. 22, n. 2, p. 166-207, maio/ago. 2017. Disponível em: https://bit.ly/3elFDc5. Acesso: 16 abr. 2021.

SOUZA, J. A Ralé brasileira: quem é e como vive. 3. ed. São Paulo: Contracorrente, 2017. E-Book.

TABOSA, H. R.; TAVARES, D. W. S.; NUNES, J. V. História e epistemologia da Ciência da Informação: abordagem social em foco. Revista Interamericana de Bibliotecología, Medellín, v. 39, n. 3, p. 289-300, sep./dic. 2016. Disponível em: https://bit.ly/2NWJDCQ. Acesso em: 12 mar. 2021.

TRIVELATO, R. M. S.; MOURA, M. A. A Diversidade cultural e os sistemas de representação da informação. In: CONGRESSO BRASILEIRO EM ORGANIZAÇÃO E REPRESENTAÇÃO DO CONHECIMENTO, 2., 2017, Recife. Anais [...]. Recife: ISKO-Brasil, 2017. Disponível em: https://bit.ly/2gJmTd6. Acesso em: 12 mar. 2021.

VARELA, A.; BARBOSA, M. L. A. A Dimensão social e cognitiva na organização e representação do conhecimento. In: CONGRESSO BRASILEIRO EM ORGANIZAÇÃO E REPRESENTAÇÃO DO CONHECIMENTO, 1., 2012, Marília. Anais [...]. Marília: ISKO-Brasil, 2012. Disponível em: https://bit.ly/2ttp8oc. Acesso em: 19 fev. 2021.

VARELA, A.; BARBOSA, M. L. A. O caráter técnico, social e mediador da organização do conhecimento. In: CONGRESSO BRASILEIRO EM ORGANIZAÇÃO E REPRESENTAÇÃO DO CONHECIMENTO, 2., 2013, Rio de Janeiro. Anais [...]. Rio de Janeiro: ISKO-Brasil, 2013. Disponível em: https://bit.ly/2ttp8oc. Acesso em: 19 fev. 2021. 


\title{
SOCIOCULTURAL KNOWLEDGE REPRESENTATION (SKR): AN ANALYSIS FROM THE THOUGHT OF ANTONIO GARCIA GUTIERREZ AND BOAVENTURA DE SOUZA SANTOS
}

\begin{abstract}
This article Aims to present an alternative view of an interdisciplinary approach to Knowledge Representation based on the approximation between Antonio Garcia-Gutierrez's Declassification of Knowledge and Boaventura de Sousa Santos's Decolonization of Knowledge, in order to contribute to a Sociocultural Knowledge Representation (SKR). In order to answer what was raised, a theoretical, bibliographic and exploratory research is used as Methodology, and having a qualitative position as a typology. This investigation is seen as a primal Result, the fact that it reveals that in order to work with SKR, in advance, it is important to "undress" the dominant thought, making it necessary to rethink around traditional information, theories, methods and practices, because it is only possible to think from the perspective and logic of Declassification and Decolonization of Knowledge, if it is mentally favored a Cognitive Reconnection and resignification of the experience in search of a movement that provides a dialectical, critical, constructivist and intersectional perception. In function, it is shown as a central Conclusion, the fact of still observing the lack of more investigative investments in research directed to the process of Declassification and Decolonization of Knowledge, with a view to showing the information professional that there are alternative possibilities of performance, whether in the academic, political scope or towards society.
\end{abstract}

Descriptors: Sociocultural Knowledge Representation (SKR). Knowledge Representation. Declassification of Knowledge. Decolonization of Knowledge. Sociology of Knowledge.

\section{REPRESENTACIÓN SOCIOCULTURAL DEL CONOCIMIENTO (RSC): ANÁLISIS DEL PENSAMIENTO DE ANTONIO GARCIA GUTIERREZ Y BOAVENTURA DE SOUZA SANTOS}

\section{RESUMEN}

Esta investigación tiene por Objetivo presentar una visión alternativa de abordaje interdisciplinario de la Representación del Conocimiento a partir de la aproximación entre la Descalificación del Conocimiento de Antonio García Gutiérrez y la Descolonización del Conocimiento de Boaventura de Sousa Santos, con el fin de contribuir a una Representación Sociocultural del Conocimiento (RSE). Para dar respuesta a lo planteado se utiliza como Metodología una investigación teórica, bibliográfica y exploratoria, y que tiene un posicionamiento cualitativo como tipología. Esta investigación se ve como un Resultado primordial, el hecho de que revela que para trabajar con la RSE, de manera anticipada, es importante "desnudar" el pensamiento dominante, por lo que es necesario repensar en torno a las teorías, métodos y prácticas tradicionales de la información. porque solo es posible pensar desde la perspectiva y lógica de la Desclasificación y Descolonización del Conocimiento, si se favorece mentalmente por una reconexión cognitiva y redefinición de la experiencia en busca de un movimiento que brinde una percepción dialéctica, crítica, constructivista e interseccional. Así, se muestra como Conclusión central, el hecho de seguir observando la falta de más inversiones investigativas en investigaciones dirigidas al proceso 
de Desclasificación y Descolonización del Conocimiento, con miras a mostrar al profesional de la información que existen posibilidades alternativas de actuación, sea en el ámbito académico, político o social.

Descriptores: Representación del Conocimiento Sociocultural (RCS). Representación del Conocimiento. Descalificación de Conocimiento. Descolonización del Conocimiento. Sociología del Conocimiento.

Agradecimentos: Programa de Pós-Graduação em Ciência da Informação da Universidade Federal da Paraíba (PPGCI-UFPB).

Recebido em: 28.04.2021

Aceito em: 17.12.2021 